\title{
Participating in diagnostic experience: adults with neuropsychiatric disorders
}

Caroline Sandell, Anette Kjellberg and Renee Taylor

\section{Linköping University Post Print}

\section{Tweet}

N.B.: When citing this work, cite the original article.

Original Publication:

Caroline Sandell, Anette Kjellberg and Renee Taylor, Participating in diagnostic experience: adults with neuropsychiatric disorders, 2013, Scandinavian Journal of Occupational Therapy, (20), 2, 136-142.

http://dx.doi.org/10.3109/11038128.2012.741621

Copyright: Informa Healthcare http://informahealthcare.com/

Postprint available at: Linköping University Electronic Press http://urn.kb.se/resolve?urn=urn:nbn:se:liu:diva-86484 
Participating in Diagnostic Experience: Adults with Neuropsychiatric Disorders

\title{
Authors
}

Caroline Sandell, MScOT, RegOT. Neuropsychiatric Unit, County Council of Östergötland, Linköping, Sweden.

Anette Kjellberg, PhD, RegOT. Department of Social and Welfare studies, Linköping University, Sweden.

Renée R. Taylor, PhD, Professor, Department of Occupational Therapy, University of Illinois at Chicago, Chicago, Illinois, U.S.A. \& Department of Social and Welfare studies, Linköping University, Sweden.

\section{Corresponding author}

Address for correspondence:

\author{
Anette Kjellberg \\ Faculty of Health Sciences \\ Department of Social and Welfare Studies \\ SE-601 74 Norrköping \\ Sweden \\ Telephone: + 4611363279 \\ Telefax: + 4611125448 \\ E-mail: anette.kjellberg@.liu.se
}

\section{Running headline: Participating in Diagnostic Experience}




\begin{abstract}
Knowledge about neuropsychiatric disabilities has increased in recent years, resulting in an increasing number of adults requesting neuropsychiatric evaluation. The aim of this qualitative study was to describe adult clients' experiences of participating actively in a supportive assessment process in which they received a diagnosis of either Autism spectrum disorder (ASD) and/or Attention-Deficit Hyperactivity Disorder (ADHD) and then received follow-up counselling, guidance, and compensatory resources that were immediate and directly integrated into the diagnostic experience. The Occupational Performance History Interview - Second Version (OPHI-II) was selected because it is client-centered. It measures how a significant life event affects a person's occupational identity, occupational competence, and interaction with the environment. The OPHI-II was administered to capture 15 participants' experiences of being diagnosed with ASD and/or ADHD as the significant life event of focus. Three categories were formed by using qualitative content analysis: (I) strengthened occupational identity; (II) compensatory support enhances occupational competence, and (III) effects of the social environment on relationships. Findings indicated that the diagnostic experience had transformative effects on participants' occupational identities, occupational competence, and ability to self-advocate for increased understanding and resources within their environments. Implications of these findings and future research are discussed.
\end{abstract}

Key words: assessment, attention deficit hyperactivity disorder, autism spectrum disorder, cognitive assistive devices, evaluation, intervention, occupational therapy, OPHI-II 


\section{Participating in Diagnostic Experience: Adults with Neuropsychiatric Disorders}

\section{Introduction}

Awareness of neuropsychiatric disabilities has increased generally within society, with a growing number of adults seeking evaluation for equivocal but familiar symptoms (1-4). Autism spectrum disorder (ASD) is an umbrella term for several diagnoses including autistic syndrome, Asperger's syndrome, atypical autism, and pervasive developmental disorder, not otherwise specified (4-8). Adults with ASD may experience difficulties with executive functioning, cognitive processing, sensory processing, and social interactions at home, in the community, and in the workplace. Clients with ASD report misunderstanding others and social situations, being misunderstood, being intimidated by others, and experiencing social rejection and loneliness (9).

Attention-Deficit Hyperactivity Disorder (ADHD) is a similarly broad term encompassing difficulties with attention, hyperactivity and impulsivity, or both. Although once characterized as a disorder of childhood and adolescence, recent research has found that it may persist into adulthood or emerge newly during adulthood, affecting

$1-6 \%$ of the adult population. Similar to adults with ASD, individuals with ADHD experience disruption in executive functioning, cognitive processing and difficulty in relationships, at work, and in relationships and organization in the home setting (10). Comorbid psychiatric diagnosis occurs in 70-75\% among adults with ADHD $(11,12)$. Depression and anxiety, as well as generally heightened physiological and psychological stress responses, are prevalent for adults with either disorder (ASD or ADHD) (13-16).

To date, there are relatively few studies of adults with ASD and ADHD in occupational therapy. Those that do exist focus on assessment or remedial approaches $(17,18)$. For example, Capo (19) argued that the role of the occupational therapist is to give support in 
the workplace through technology and through knowledge of the disability and the demands that exist at various workplaces. Others emphasize the role of participation in the occupational lives of people with ASD and ADHD (19-21).

Research has shown that receiving a psychiatric diagnosis in adulthood may include three reactions. First, psychiatric symptoms are often life-long, but the client typically lacks insight into them, particularly when it comes to having ADHD or ASD. Secondly, psychiatric disorders are typically not progressive and are very idiosyncratic and so there is no information on the typical course or prognosis of the disorder. Thirdly receiving a diagnosis of a psychiatric disorder may be experienced as highly stigmatizing (4).

Few studies have focused on adult clients' reactions to receiving a psychiatric diagnosis. Among these, studies indicate that clients receiving a psychiatric diagnosis can lead to negative reactions, such as feelings of rejection, stigmatization, or labelling (22). Some research suggests that receiving a diagnosis of ASD or ADHD may be particularly difficult to cope with, particularly if one's personality tends toward internalization and if the health provider has difficulty teasing out what might be attributable to a client's personality versus a clients executive, cognitive, and sensory functioning $(23,24)$. At the same time, a diagnosis can open up avenues for insight and for increased support and validation (4).

In Sweden, the importance of client participation in healthcare has been emphasized in several laws (25-27). It has also been highlighted in the Swedish Code of Ethics for Occupational Therapists (28). According to these guidelines, a key aspect in ensuring client participation involves facilitating client choice and autonomy. Participation in the present study is defined according to the Model of Human Occupation (MOHO). It involves providing clients with opportunities to identify problems and goals and encouraging their input in developing plans for support and intervention (29). This process of participation 
in the diagnostic experience was facilitated by use of the Occupational Performance History Interview - Second Version (OPHI-II) (30,31), a client-centered assessment based on MOHO.

The OPHI-II is a semi-structured interview designed to elicit narrative i.e., story-based information about a client's life history and performance in various occupational roles and settings. The OPHI-II measures three central constructs derived from MOHO: (1) occupational identity, (2) occupational competence, and (3) environment (30,31). According to $\mathrm{MOHO}$, occupational identity involves knowing who one is as an occupational being, having interests and an ability to identify a desired occupational lifestyle, having goals, projects, commitments, and values, having obligations and accepting responsibility, expecting success, and accurately estimating one's own abilities and limitations. Occupational competence defines an individual's ability to engage in and maintain regular habits and roles that are productive and satisfying. The environment is comprised of physical settings and social contacts that affect an individual's participation in a wide range of occupational behaviors and roles (29). In this study, the OPHI-II interview was custom-tailored for each participant and selected for use because it is client-centered. It measures how a significant life event affects a person's occupational identity, occupational competence, and interaction with the environment $(30,31)$. It is possible that increased participation in the diagnostic experience and immediate support networks may alleviate some of the potentially negative consequences of receiving a diagnosis. Participation might involve facilitating the client's opinions and feedback about the different diagnostic criteria and showing how supports may be utilized for improved occupational functioning. Therefore the aim of this study was to describe adult clients' experiences of participating actively in a supportive assessment process in which they received a diagnosis of either ASD and/or ADHD and then received follow-up counselling, guidance, and compensatory resources that were immediate and directly integrated into the diagnostic experience. 


\section{Materials and Methods}

\section{Participants}

Inclusion criteria were adult clients aged 18 years or older who had undergone a neuropsychiatric investigation at a Neuropsychiatric Outpatient Clinic (NP) during a time span of 14 months. In total thirty persons underwent a clinical evaluation during this period that resulted in receiving a diagnosis of ADHD, ASD, or both. Convenience sampling (32) was used and twenty-two of these who had got a diagnosis living geographically closest to the NP were invited to participate in an interview six months after completing all of the interventions from the NP-team. The team included a physician, nurse, physiotherapist, psychologist, and an occupational therapist.

Fifteen persons (four women and 11 men) consented to participate. Reasons for declining participation in this study included health conditions (i.e. depression) and a few were not interested. Ten received a diagnosis of ADHD and 7 received a diagnosis of ASD (two received both diagnoses). The age range was 28-53 (mean age 39 years). Eight of the participants had children and lived with a partner. Seven of the persons were employed and the rest were on sick leave, received a disability benefit from the social insurance system, or were involved in labour market programmes including such as vocational training and getting access to placement services.

\section{Procedures}

Participants were recruited from a neuropsychiatric outpatient department (NP) in a county council in Sweden. For the diagnostic experience, all participants received an interactive neuropsychiatric evaluation during which they received a diagnosis, followed by a series of immediate and integrated services from the multimodal team. Services included psychological support, medications, physiotherapy recommendations for physical training, 
occupational therapy recommendations concerning how to organise and structure daily living activities, and other support from professionals in the municipality such as the Swedish Public Employment Service (AF) and the Swedish Social Insurance Agency (FK). The entire diagnostic experience was limited to a three-month period.

Clients participated actively during the entire process, including the evaluation phase. This included active involvement in mutual dialogue with team members regarding validating and discussing assessment results. The team's view was that the clients should fully participate in the diagnostic experience. Team members made a point to listen to each client's perspectives on his or her thought processes, feelings, and behaviours. They solicited feedback and recommendations from each client. They provided opportunities for clients to accept or decline the diagnosis and select the services that the clients thought would be helpful. Clients also had the opportunity to present their own suggestions for services not traditionally offered at the facility. Thus, the diagnostic experience was characterised by full participation and collaboration between the professionals and the clients.

\section{Data Collection}

To collect data for the present study, the Swedish version of the Occupational Performance History Interview, second version (OPHI-II), $(30,31)$ was used. It was selected for its emphasis on the role of critical life events in shaping participants' perceptions of their occupational identity, competence, and interactions with the social environment. In this case, the critical event of focus was receiving a first-time diagnosis of ASD and/or ADHD. The semi-structured form gave the interviewer opportunities to adapt each interview to each participant. The interviews were digitally recorded. The length of the interviews varied between 1-2 hours. 


\section{Ethical Aspects}

The ethical guidelines from the Council for Research in the Humanities and Social Sciences (33) guided the research process. Participation was voluntary and the principle of informed consent was applied. Participants received written information about the study. Data were handled with confidentiality and in order to guarantee anonymity in this article, altered names were used for the participants.

\section{Data Analysis}

Data were analysed by using qualitative content analysis (34). The interviews were transcribed verbatim. The first step was to gain an overall picture of the data. All interviews were read through repeatedly and independently by the first and second authors. The analysis described by Hsieh and Shannon (34) implies that the coding is based on predetermined categories. The constructs occupational identity, occupational competence and social environment in the OPHI-II $(30,31)$ became the categories in the coding process. Each interview were scrutinized line by line and coded separately by the first and second author. Statements that were relevant to the aim of the study was identified and grouped into the three categories. The coding process involved reading the transcripts and going back and forth for checking that the theoretical descriptions of the constructs was correctly understood and interpreted (29-31) in relation to the statements in the transcripts. Subsequently the three authors discussed and compared the coding until consensus was reached. The three categories were labelled as "Strengthened occupational identity", "Compensatory support enhances occupational competence" and "Effects of the social environment on relationships". Peer examination in enhancing credibility (35) was carried out by one researcher having theoretical and practical knowledge in MOHO (29) and the OPHI-II (30,31). The quotes presented in the results have been chosen because they give illustrative descriptions of how the clients' described their experiences receiving a diagnosis in this particular setting. 


\section{Results}

\section{Strengthened Occupational Identity}

Findings indicated that all of the participants had significant difficulties in the area of occupational identity, but that their identities were strengthened as a result of participating in the diagnostic experience. Prior to the diagnosis, the clients described themselves as different from other people. They described the experience of receiving the diagnosis as allowing them to attach meaning to their lifelong experiences of not fitting in and to find a sense of identity as a person with a disability:

From the day the investigation was carried out and I got to know what it was all about. I wasn't stupid, it was because of the ADHD and the trait of Asperger" (Adam).

Ben stated: "When I was younger, I felt that I did not think of things like other people did and it [the diagnosis of ASD] shows that it was what it was all about.

Once the participants labelled their problems, they reported that it allowed them to achieve self-acceptance: I think it is valuable to be who I am. I do not have to pretend in any way (Alice). In addition, knowledge of the diagnosis allowed participants to accept responsibility for their occupational choices:

I think it [the diagnostic experience] was good but it is 25-30 years too late. It would have been very good if I had known this earlier, before I started school - - maybe I had [tried for] a better education (Chris).

Participants also learned to recognize their identity and to have commitments and a sense of obligation: You have learn to live with it, this is the way it is, and despite of it try to function as good as possible, that's what we are working on now (Ben).

All of these subjective experiences reported by the participants cohere with aspects of occupational identity. As a result of the diagnosis, participants were able to attach meaning to 
their past experiences and occupational choices, accurately appraise their limitations, and show a willingness to accept responsibility for the diagnosis and for its implications. They were able to recognize themselves positively as individuals with a disability and express a willingness to preserve.

\section{Compensatory Support Enhances Occupational Competence}

Through the diagnostic experience, participants gained awareness about the importance of compensatory support to sustain habits that are productive and satisfying. Immediate personal support offered as part of the diagnostic experience was critical in clients' homes, workplaces, during their leisure time, and in contact with authority:

They [the support workers] help me to take care of the mail. We open it and check what it is, we collect the dirty dishes and we [wash dishes] together. We pick up things in the apartment and clean up and perhaps vacuum or clean up the toilet and the washbasin, or around the computer and so on... (David).

Alice reported: The occupational therapist has been home several times and we have continued with this labelling of all cabinets and drawers and things like that in the [kitchen]... We have sorted [things] and [the system] works damn well.

Sometimes a work assistant travelled with participants to support employment:

I have my assistant or what you can call it and it has been a big relief. He helped me fix things like book a hotel room and arrange transportation like train tickets... Yes you know [everything like this] because [these things are] difficult for me (Eric).

In addition to personal support, assistive technologies served as important compensatory supports for the participants. The effect of these devices and strategies in everyday life increased participants' ability to sustain productive activity:

One big and heavy burden [has] fallen off my wife's shoulders due to it [the hand computer] you know... [ it helps with] time management to [remind me about] all the meeting... all of [the] things like that... The computer helps me instead of my wife... 
We call it my little brain... I have an extra memory you know (Adam).

In terms of occupational competence, medications facilitated participants' ability to concentrate and maintain focus at work: It [the medicine helps] enormously. Otherwise it's like erasing a painting... You don't know what you are doing and you have to start over and over again (Barbara).

In summary, the availability of support and the provision of choice to participants represented essential components of the diagnostic experience. These compensatory supports allowed all participants to experience a new or renewed sense of occupational competence in their functioning in one or more of their everyday environments.

\section{Effects of the Social Environment on Relationships}

The social environment provided during the diagnostic experience led participants to achieve an increased understanding of others. Over the course of their lives, participants reported lacking understanding from others, including other health care professionals, who expressed doubts about the diagnosis of adult ADHD: It makes me sad... You are already sad and you don't have to sit and defend yourself in front of your doctor (Carol). Participants also report being treated with mistrust by family members, who, over the years, sometimes told them they were lazy and that they could do things if they wanted. As a result of learning about themselves through the diagnostic experience, participants' feelings of suspicion was transformed into feelings of understanding. They began to see some of the same behaviours in first-degree relatives and were able to develop an understanding of those behaviours. Many felt validated and heard: After the first visit, [at the centre] it was like heaven, it was positive; I didn't have to feel misunderstood (Diana). The diagnostic experience was positive because of its focus on the client as a person. Clients reported that 
they didn't have time to put up defensive walls, they couldn't escape into their own minds, and they were guided to think about their disability in a positive way. They felt actively involved in the evaluation:

You got to know things [and] all the time you got to take part in the results when doing the tests and shit... you got to take part in what was written in the chart and so on... then you really see [the diagnosis] is a written thing, it's not any damned guesses (Fredric).

To be treated with understanding and respect by the multimodal team was described as very valuable by all participants.

\section{Discussion}

The aim of this qualitative study was to describe adult clients' experiences of participating actively in a supportive assessment process in which they received a diagnosis. Findings from a similar study by Horn and associates (22) called for changes to be made in the way certain psychiatric diagnoses, such as borderline personality disorder, are communicated to clients and responded to by practitioners. Perspectives of participants in the Horn et al. (22) study conveyed that the experience of receiving a diagnosis was only helpful if it led to support or gave them something concrete to work on in terms of self-acceptance and behavioural change. Findings from our study suggest that the unique diagnostic experience provided for adults with ASD and/or ADHD led to feelings of support, a stronger sense of occupational identity and competence, and improved relationships.

As a result of the diagnostic experience, knowledge gained about the diagnosis and its consequences for daily living influenced participants' occupational identities, perceived occupational competency, and their relationships within the social environment. According to Kielhofner (29), occupational identity refers to a deeper understanding of one's capacity, relationships with others, and expectations of other people in the environment. 
Participants' descriptions of how the diagnosis allowed them to accept themselves and understand their strengths and limitations are also dimensions of occupational identity.

From a MOHO perspective (29), understanding the individual's earlier life experiences before the diagnosis is a cornerstone in supporting them to develop competence in everyday life activities. In this study, the OPHI-II $(30,31)$ allowed for this understanding to occur so that participant could re-discover themselves as individuals with a disability and find new meaning in their occupational roles and in their relationships with others. Participants' reports offered a potential starting point for the development of other aspects of occupational identity, such as the ability to identify a desired occupational lifestyle, to pursue goals and projects, and to expect success. With additional support, compensatory devices, and a positive social milieu, it is possible that the occupational identities of participants would continue to grow over time.

Additionally, the knowledge that participants gained about their behaviors and reactions also allowed them to use supports and adaptations to achieve a higher level of independence, choice, and participation. These changes were apparent to participants at home, in the community, and at work. Compensatory cognitive supports such as personal assistants, work assistants, and assistive technologies enabled participants to develop new roles and to maintain regular habits that were productive and satisfying. This corresponds with Kooij's et al. (36) coaching program for clients with ADHD focusing on strategies for time management and structuring home activities. Participants also reported receiving useful recommendations from occupational therapists, and this finding was consistent with that of Capo (19), who reported that occupational therapists can contribute with evaluations, job placement, and in supervising personal assistants for people at work i.e. job coaches. 
Moreover, the support and validation provided by the team during diagnostic experience allowed participants to understand others and improve their relationships. Through this experience, participants learned to be cautious not to over-rely on family members, to request supports and resources outside of the family and within the community, and to communicate openly with care providers. Although these results are promising, further research will be necessary to test this unique approach to diagnosis on a larger sample and on individuals with other types of psychiatric disorders.

An important implication of this study is that client participation in the diagnostic experience appeared to lead to positive outcomes and follow-through on team members' recommendations. There is an increasing need in occupational therapy to build upon participatory approaches as a standard of therapy (25-27) and as an important aspect of education for professionals, clients and caregivers - particularly for these more severely impaired neuropsychiatric populations.

\section{Methodological Considerations and Future Research}

This study employed a qualitative approach that focused on the clients' experiences of the evaluation and intervention program. We chose our approach because, to our knowledge, studies like this have not yet been performed in occupational therapy with these populations. However, because of this approach and due to the small sample size, the study's results do not claim to generalize. It was an advantage that the OPHI-II $(30,31)$ provided the opportunity to focus on a specific event, - receiving a first-time diagnosis through the neuropsychiatric evaluation and intervention program. Because the OPHI-II is flexible, dynamic, and semi-structured the interviewer was able to tailor the interview questions for each participant. This supported the validity of the study because participants differed in their approach to responding to questions. Several steps were taken to maximize 
trustworthiness. Credibility was enhanced through the ongoing adaptations to the questions in the OPHI-II to each participant and through the use of probes which ensured that the informants had opportunities to share their experiences. Dependability and conformability were addressed through the use of verbatim transcripts and the involvement of the three investigators in the data analysis (35).

In future studies, it will be important to isolate the exact mechanisms of change i.e., the specific statements and behaviours on the part of the team that led clients to participate positively in the diagnostic experience. It may not be serendipitous that the central interview measure used in this study to elicit client perspectives the OPHI-II, a measure based on the Model of Human Occupation (29), may have influenced the way in which participants responded. Moreover, it will be important to determine whether our findings were unique to adults with ASD and ADHD, or whether they might be generalized to individuals with other types of psychiatric disorders, including personality disorders.

Research comparing different approaches to diagnosis for different diagnostic groups is needed to establish the specific aspects of our approach that were most successful. For example, research might compare the effects of psychoeducational strategies versus collaborative strategies like those described herein. Additionally, studies will need to isolate specific interpersonal characteristics, psychological resiliencies, cultural features, and other ways communicating within our client population that may have predisposed them to report a positive diagnostic experience in our study.

\section{Acknowledgements}

The authors wish to acknowledge the Swedish Association of Occupational Therapists whose grants supported this research. 


\section{References}

1. Nylander L, Holmqvist M, Zettervall K. Utredning av barnneuropsykiatriska tillstånd hos vuxna ofta önskvärt. Funktionshinder kan leda till social missanpassning. Läkartidningen 2002;99:1692-99.

2. Wing L. Reflections of opening Pandoras box. J Autism Dev Disord 2005;35:197-203.

3. Barkley R, Murphy KR, Fisher M. ADHD in adults what the science says New York: Guilford publication; 2008.

4. Punshon C, Skirrow P, Murphy, G. The 'not guilty verdict': Psychological reactions to a diagnosis of Asperger syndrome in adulthood. Autism 2009;13:265-83.

5. Association. Diagnostic and statistical manual of mental disorders, DSM-IV-TR. Washington: American Psychiatric Association, 2000.

6. World Health Organization. Pocket guide to the ICD-10 Classification Of Mental and Behavioral Disorder. China: Churchill Livingstone. 1994.

7. Nylander L, Gillberg C. Screening for autismspectrumdisorder in adult psychiatric outpatients: a preliminary rapport. Acta Psychiatr Scand 2001;103:428-34.

8. Wing L. The autistic spectrum - A guide for parents and professionals. London: Constable; 1996.

9. Portway SM, Johnson B. Do you know I have Asperger's syndrome? Risks of a non-obvious disability. Health, Risk, \& Society 2005;7:73-83.

10. Katz LJ. ADHD in adults: The syndrome and its reconceptualization. In: Katz LJ, Lynda J. Contemporary Neurobehavioral Syndromes. New York, NY, US: Psychology Press, 2011:71-109.

11. Angold A, Costello EJ, Erkanli A. Comorbidity. J Child Adolesc Psychiatry 1999; 40: 57-87.

12. Biederman J. Impact of comorbidity in adults with attention deficit/hyperactivity disorder. J Clin Psychiatry 2004; 65: (Suppl.3): 3-7.

13. Fischer M, Barkley RA, Smallish L, Fletcher K. Young adult follow-up of hyperactive children: Selfreported psychiatric disorders, comorbidity and the role of childhood conduct problems. J Abnorm Child Psychol 2002; 30:463-75.

14. McGough JJ, Smalley SL, McCracken JT, Yang M, Del'Homme M, Lynn DE, et al. Psychiatric comorbidity in adult attention deficit hyperactivity disorder: Findings from multiplex families. Am J Psychiatry 2005;162:1621-627.

15. Wilens TE, Biederman J, Spencer TJ. Attention deficit/hyperactivity disorder across the lifespan. Annu Rev Med 2002; 53:113-31.

16. Lackschewitz H, Huther G, Kroner-Herwig, B. Physiological and psychological stress responses in adults with attention-deficit/hyperactivity disorder (ADHD). Psychoneuroendocrinology 2008;33:612-24.

17. Dunn W, Myles BS, Orr, S. Sensory processing issues associated with asperger syndrome: A preliminary investigation. Am J Occup Ther 2002; 56:97-102.

18. Brown CE, Dunn W. Adolescents/Adult Sensory Profile. Users manual. San Antonio: The psychological Corporation; 2002.

19. Capo LC. Autism, employment, and the role of occupational therapy. Work 2001; 16: 201-7.

20. Gutman SA. Szczepanski M. Adults with Attention Deficit Hyperactive Disorder: Implication for occupational therapy intervention. Occup Ther Ment Health 2005; 21:13-37. 
21. Watling R, Tomchek S, LaVesser P.The scope of occupational therapy services for individuals with autism spectrum disorders across the lifespann. Am J Occup Ther 2005; 59:680-83.

22. Horn N, Johnstone L, Brooke S. Some service user perspectives on the diagnosis of borderline personality disorder. J Ment Health 2007;16:255-69.

23. Kessler RC, Greif-Green J, Adler LA, Barkley RA, Chatterji S, Faraon SV, et al. Structure and diagnosis of adult attention-deficit/hyperactivity disorder. Arch Gen Psychiatry 2010;67:1168-78.

24. Ratey JJ, Miller AC, Nadeau KG. Special diagnostic and treatment considerations in women with attention deficit disorder. In: Ratey JJ, Miller AC, Nadeau KG. A comprehensive guide to Attention Deficit Disorder in Adults: Research, diagnosis, and treatment. Philadelphia, PA, US: Brunner/Mazel, 1995:260-83.

25. SFS. 1982:763. Hälso- och sjukvårdslag (The Social Service and Medical Act). In Swedish. Stockholm: Socialdepartementet; 1982.

26. SFS. 2001:453. Socialtjänstlag (The Social Service Act). In Swedish. Stockholm: Socialdepartementet; 2001.

27. SFS. 1993:387. Lag om stöd och service till vissa funktionshindrade (The Act concerning support and service for persons with certain functional impairments). In Swedish. Stockholm: Socialdepartementet; 2001.

28. Swedish Association of Occupational Therapists. Code of ethics for occupational therapists. Nacka: Swedish Association of Occupational Therapists; 2005.

29. Kielhofner G. Model of Human Occupation: Theory and application. 4th ed. Baltimore: Lippincott Williams \& Wilkins; 2008.

30. Haglund L, Svensson H, Wärnelius H. Occupational Performance History Interview, svensk version, version 1. Linköping: Hälsouniversitetet; 2000.

31. Kielhofner G. Mallinson T, Crawford C, Nowak M, Rigby M, Henry A, Wales D. The Occupational Performance History Interview (version 2.1) OPHI-II. Model of Human Occupation Clearinghouse, department of Occupational Therapy, College of Applied Health Sciences, University of Illinois Chicago: 2004.

32. Patton MQ. Qualitative research and evaluation. $3^{\text {rd }}$ ed. London: Sage; 2002.

33. Vetenskapsrådet. Forskningsetiska principer i humanistisk-samhällsvetenskaplig forskning (Research ethical principles in humanistic and social science). In Swedish. Available at http://www.codex.vr.se/texts/HSFR.pdf (Accessed 6 September 2010).

34. Hsieh HF, Shannon, SE. Three approaches to qualitative content analysis. Qual Health Res 2005;15:1277-88.

35. Krefting L. Rigor in qualitative research: the assessment of trustworthiness. Am J Occup Ther 1991;45:21422.

36.Kooij JJS, Bejerot S, Blackwell A, Caci H, Casas-Brugué M, Carpentier PJ, et al. European consensus statement on diagnosis and treatment of adult ADHD: The European Network Adult ADHD. BMC Psychiatry 2010;67:1-24. 